\title{
A INFLUÊNCIA DAS POLÍTICAS PÚBLICAS NO PROCESSO DE OCUPAÇÃO E URBANIZAÇÃO DA MESORREGIÃO NORTE MATO-GROSSENSE
}

\author{
PUBLIC POLICIES INFLUENCE ON THE PROCESSES OF OCCUPATION \\ AND URBANIZATION IN NORTHERN MATO GROSSO MESOREGION
}

\author{
Marines Orlandi* \\ Zelimar Soares Bidarra** \\ Arnaldo Taveira Chioveto***
}

\begin{abstract}
RESUMO
O estudo identifica a interferência das políticas públicas para o processo de ocupação e urbanização da mesorregião Norte Mato-grossense, a partir de 1970. Mostra o papel do Estado-Nação no surgimento e crescimento de um Estado, com uso de fomento de recursos e infraestrutura básica para ocupação de um contingente de população que vinha das migrações internas do país. Com uso de análise bibliográfica e documental, mostra a expansão do espaço urbano, as modificações e estruturações da mesorregião. Com tal análise, a reestruturação territorial, mediante a oferta de infraestrutura básica (iluminação elétrica, água canalizada e instalações sanitárias), fortaleceu a área urbana e suas atividades fundamentais de geração de trabalho e renda. A compreensão a que se chega é que tal fato tem refletido significativamente no crescimento e concentração populacional, tanto no aspecto da urbanização das cidades, como nos da economia urbana e regional.
\end{abstract}

Palavra-Chaves: Desenvolvimento urbano. Mato Grosso. Políticas públicas. Território.

\begin{abstract}
The study identifies how public policies interference in the processes of occupation and urbanization of the Northern Mato Grosso mesoregion that started in 1970. It shows the role of the Nation-State on the rise and growth of a state, by the provisions of resources and basic infrastructure to the settlement of a population coming from the country's internal migrations. The study included a bibliographic and documental analysis and shows the expansion of urban space, modifications

\footnotetext{
" Doutoranda em Desenvolvimento Regional e Agronegócio pela Universidade Estadual do Oeste do Paraná (Unioeste), mestre em Administração pela Faculdade Evangélica de São Paulo (FAESP) graduada em Administração pela Universidade Paranaense (Unipar). Email: marinesorlandi@gmail.com

** Doutora em Educação pela Universidade de Campinas (Unicamp), mestre em Serviço Social pela Universidade Federal do Rio de Janeiro (UFRJ) e graduada em Serviço Social pela Universidade Federal Fluminense (UFF). Professora adjunta do colegiado do curso de Serviço Social e do Programa de Pós-Graduação em Desenvolvimento Regional e Agronegócio da Universidade Estadual do Oeste do Paraná (UNIOESTE). Email: zelimar@yahoo.com.br

${ }^{* * *}$ Mestrando em Desenvolvimento Regional e Agronegócio pela Universidade Estadual do Oeste do Paraná (Unioeste), graduado em Tecnologia Civil de Obras em Solos pela Universidade Estadual de Campinas (Unicamp).Email: arnaldotc@gmail.com
} 
and the structure of the mesoregion. The analysis demonstrates that the territorial restructuration, by the provision of basic infrastructure (electric lightning, piped water, sanitary facilities), strengthened the urban area and its fundamental activities which generate work and income. The study reveals that such fact has been reflecting in a significant way in the population growth and concentration, not only in the cities urbanization aspect but also in the urban and regional economy aspects.

Keywords: Urban development. Mato Grosso. Public policies. Territory.

\section{Introdução}

O objetivo do artigo é identificar e refletir o modo pelo qual as políticas públicas de ocupação territorial e urbanização da mesorregião Norte Mato-Grossense, a partir de 1970, determinaram a formação de infraestrutura urbana básica caracterizada por iluminação elétrica, água canalizada e instalações sanitárias. Estes foram fatores que contribuíram para o crescimento urbano no Estado e a distribuição da população no território. Uma vez que a política pública representa a ideia da:

$[\ldots]$ coisa de todos [...] que compromete simultaneamente o Estado e a sociedade. Política Pública significa, portanto, ação coletiva que tem por função concretizar direitos sociais demandados pela sociedade e previstos nas leis. Ou, em outros termos, os direitos declarados e garantidos nas leis só têm aplicabilidade por meio de políticas públicas correspondentes, as quais, por sua vez, operacionalizam-se mediante programas, projetos e serviços (...) (PEREIRA, 2002, p. 222ss).

Vale ressaltar que o período histórico estudado foi marcado por grandes transformações na economia brasileira, como mudanças macroeconômicas e regionais, no que tange ao perfil da divisão social do trabalho e da distribuição espacial das atividades produtivas. E nos aspectos políticos, principalmente com o restabelecimento da democracia, ao final dos anos de 1980.

Na esfera da gestão estatal conviveu-se com a busca pela democratização dos espaços de gestão das políticas públicas, defendida, segundo Mafra (2009), em razão da implementação dessas políticas envolverem inúmeros conflitos, comumente relacionados às formas de satisfação das necessidades da população. A política pública sintetiza os modos/arranjos para promover o acesso dos membros da classe trabalhadora aos bens de consumo coletivo que são criados a partir da riqueza social.

Porém, no curso da transformação das intenções políticas em ações e práticas, podem ocorrer desvirtuamentos que comprometem questões de investimento e orçamento. É importante destacar que estes conflitos de interesses estão latentes nos resultados dos investimentos governamentais que construíram o cenário do desenvolvimento econômico-social de Mato Grosso.

Daí a importância dos estudos e as análises sobre os processos de regionalização e a diferenciação das áreas em um determinado território. Ao estudar as diferenças e semelhanças de um espaço territorial, se sobressaem as disparidades e as desigualdades decorrentes de características geográficas, clima e solo, bem como dos grupos e seus variados referenciais culturais, sociais e econômicos, os quais corroboram na estruturação de uma região. Assim, tratar da regionalização requer considerar alguns fatores, como: mundialização da economia, modernização, tecnologias de ponta e produção sustentável. Isso pode ser percebido na perspectiva de Correa (2002, p. 49), que afirma: "No capitalismo, [dado que] as regiões de planejamento são unidades territoriais através das quais um discurso da recuperação e desenvolvimento é aplicado".

Por sua vez, a "recuperação e desenvolvimento" podem ser detectados, segundo Harvey (2007), pelo surgimento de novas formas de produção, novas maneiras de ofertas de serviços e novos mercados, o que impulsiona a inovação. Todavia, esse desenvolvimento impulsiona também a concentração das atividades produtivas, resultando no fortalecimento de centros urbanos delineados a partir de novas roupagens de áreas, antes rurais, tal como na moderni- 
zação, tecnificação e industrialização da agricultura, que modificou a paisagem e a densidade demográfica rural (ALVES, FERRERA DE LIMA e SOUZA, 2009).

Através dessa forma de reestruturação produtiva e econômica, fortaleceram-se as áreas urbanas (e metropolitanas) e suas atividades econômicas fundamentais, tanto as secundárias e terciárias, refletindo significativamente no crescimento e concentração populacional, bem como nos aspectos da economia urbana e regional.

É importante reconhecer que na mesorregião Norte Mato-Grossense tais modificações produziram interferências a partir de auxílio de políticas públicas advindas das esferas federal, estadual e municipal. Elas incrementaram recursos, tanto financeiros como infraestruturais, que favoreceram à mobilidade espacial da população em determinado território e, com isso, fortaleceram a expansão da área urbana.

Desse modo, captar e compreender as influências produzidas pelas políticas de ocupação e urbanização da mesorregião Norte Mato-Grossense, num cenário deficitário de informações e indicadores sistematizados, é essencial para subsidiar as futuras políticas locais e o planejamento regional.

\section{Referencial Teórico}

\section{A ocupação pela via da integração do espaço}

O estado de Mato Grosso é composto por uma variedade de ambientes físicos e diferenciadas formas de ocupação. Higa (2005) comenta que dada sua localização privilegiada, considerando o território transfronteiriço internacional, do qual faz parte a Amazônia Legal, cabe-lhe a condição de espaço estratégico. Em face disso, foi-lhe atribuído papel relevante nos planos de desenvolvimento nacional e de integração sul-americana. Em virtude dessa localização e de interesses políticos, a partir da década de 1970 passou a receber estímulos governamentais (diversos programas federal e estadual) para que se efetivasse a ocupação de seu território, o que o transformou em um dos maiores produtores agropecuários do Brasil.

Esse processo provocou a interiorização da agropecuária, o crescimento ocupacional e a urbanização, fatores que contribuíram para contínuas subdivisões territoriais, originando dezenas de no- vos municípios entre as décadas de 1970 a 2000 . No entanto, a dispersão populacional e o crescimento econômico não se deram de forma linear.

$\mathrm{Na}$ mesorregião Norte Mato-Grossense, nos anos de 1970, segundo Moreno (2005), havia apenas 4 municípios em uma área de aproximada de $482.748,774 \mathrm{~km}^{2}$. Nos anos de 1980 eram 10 municípios; em 1991 havia 33 municípios; nos anos 2000 estavam constituídos 49 municípios e em 2010 passou-se a contar com os atuais 55 municípios (IBGE, 2011). O crescimento ocupacional e a urbanização ocorreram mediante mudanças significativas nos aspectos de infraestrutura, propiciados pelos programas de desenvolvimento regional de Mato Grosso, pautado pelo acesso a recursos com vistas à modernização do meio rural e urbano. Na década de 1970 , teve início a expansão e a melhoria do sistema viário estadual, o que viabilizou a interiorização da população, a intensificação das atividades agropecuárias e a expansão da infraestrutura física e social. Isso repercutiu nas condições de vida, saúde, saneamento, educação, trabalho e renda.

Nesse contexto, o crescimento populacional esteve ligado, principalmente, à construção das rodovias federais, aos projetos de colonização, público e privado, ao baixo preço da terra agricultável e aos programas federais de incentivos fiscais e de desenvolvimento regional. Em 1980, registrou-se crescimento populacional de $85,79 \%$ (MORENO, 2005), em razão das políticas implantadas. Os censos demográficos de 1991 e 2000 mostraram uma desaceleração do processo de crescimento populacional, o que pode ser explicado pela diminuição dos incentivos governamentais, aumento da valorização das terras agricultáveis e da mudança na estrutura produtiva do estado, o que provocou desemprego, êxodo rural e diminuição do fluxo migratório.

Tais acontecimentos corroboram com o que Becker (2001) afirmou sobre a Amazônia. Para ela, a ocupação polarizada daquela região se fez a partir de "surtos", ligados à valorização momentânea de produtos no mercado internacional, seguidos de longos períodos de estagnação. Na perspectiva de Moreno e Higa (2005), isso resultou no crescimento diferenciado da população, o qual foi proporcional aos atrativos oferecidos por cada região. A descontinuidade da ocupação ocorreu nas áreas dotadas de maior infraestrutura e onde houve maiores investimentos. 
Foram essas regiões as que se tornaram atrativas para as frentes de migração, principalmente, vindas do Sul e Sudeste do país (PEREIRA, 2007).

Desde a década de 1930, os recursos para atração de migrantes vieram do planejamento governamental, via implementação de programas e de políticas públicas federais (HIGA, 2005). Esta forma de intervenção governamental intensificou-se após a crise cafeeira, ocorrida no governo de Vargas, o qual adotou medidas para a ocupação e interiorização do país através do programa "Marcha para o Oeste", cujo objetivo era o de integrar os "espaços vazios" do interior à economia nacional.
De acordo com Siqueira (1990), para o governo federal, o Mato Grosso era como um grande "vazio demográfico", cujas terras poderiam ser integradas ao processo produtivo para aliviar as pressões sociais que aconteciam nos centros urbano-industriais. No governo de Juscelino Kubistchek, o estado de Mato Grosso foi incorporado ao processo de integração nacional, quando da implantação do "Plano de Metas". Para esta integração, a capital federal foi transferida do Rio de Janeiro para o planalto central, o que desencadeou a construção de rodovias, como a Transamazônica, Perimetral Norte (BR-158), Cuiabá-Santarém (BR-163) e Cuiabá-Porto Velho (BR-174).

Figura 1 - Mapa de rodovias federais e estaduais de Mato Grosso - 2011
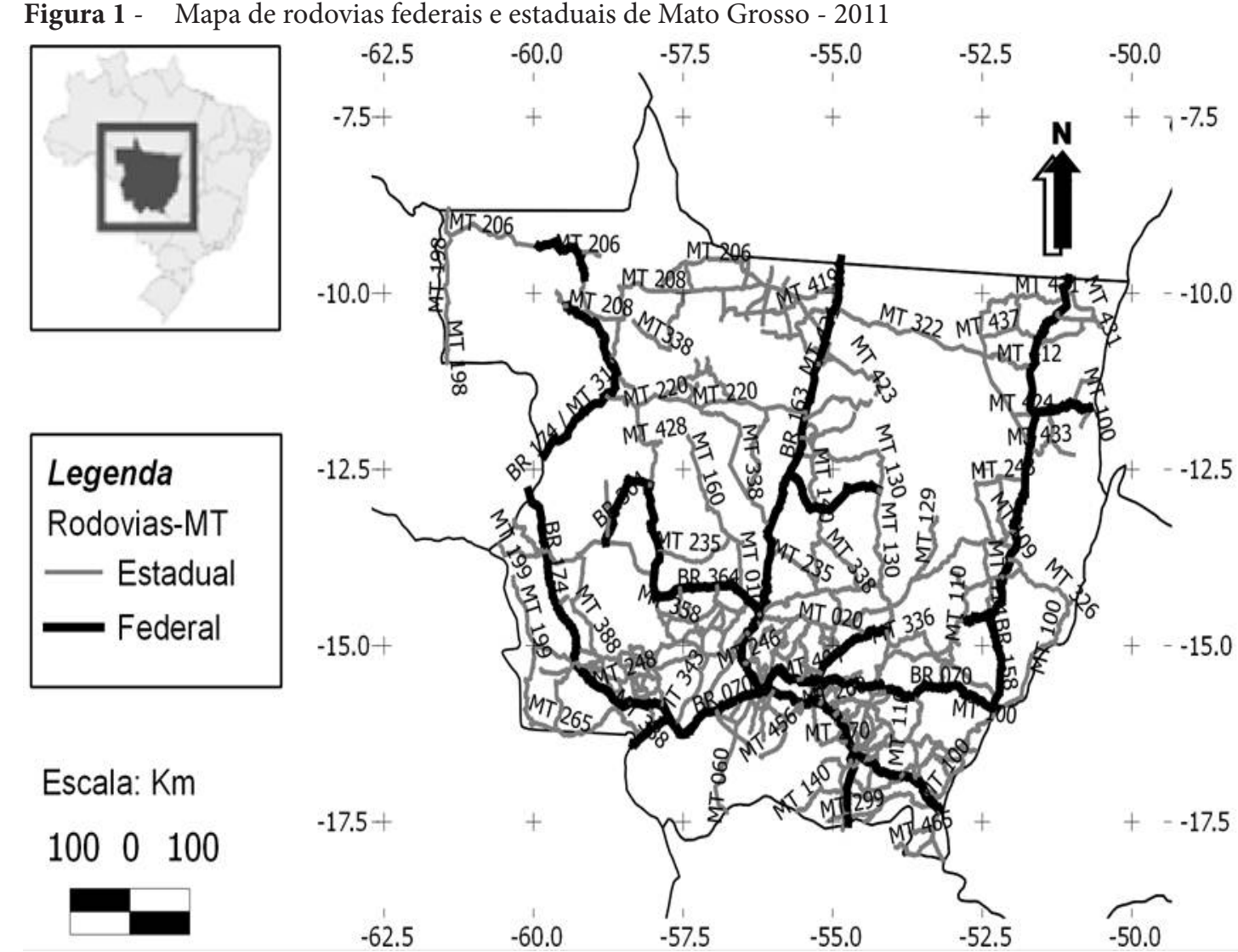

Fonte: Dados da pesquisa (2011).

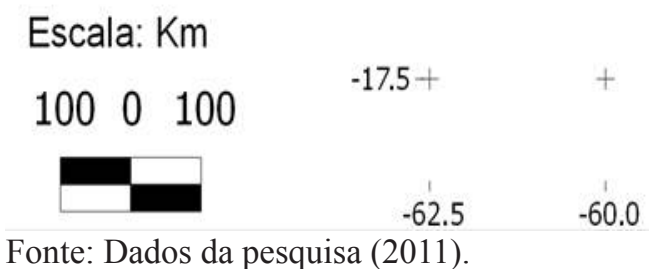

Segundo Pereira (2007), a construção da BR 163 (Cuiabá-Santarém) teve a função de integrar a Amazônia brasileira ao Sul e Sudeste do país, ligando o estado do Rio Grande do Sul ao estado do Pará, passando por Mato Grosso, estimulando a integração entre os municípios situados ao longo do seu traçado. Esta ação foi determinante para a integralização do espaço e a atração de população para o seu entorno. Com a abertura de rodovias estaduais ocorreu a interiorização e a urbanização do espaço.
De acordo com Moreno (2005), a partir da década de 1970, a definição de novos espaços econômicos foi orientada pela "Política de Integração Nacional" com base na dinamização de setores das economias regionais. Nesse sentido, sob o governo militar de Médici, foi criado o Plano de Integração Nacional (PIN), cujo lema era "integrar para não entregar", reiterando o objetivo de ocupar os espaços vazios na Amazônia, incorporando-os à acumulação 
de capital. Com o PIN, o governo pretendeu transferir cerca de 300 (trezentas) mil famílias, principalmente nordestinas, para os projetos oficiais de colonização às margens das rodovias Transamazônica e Cuiabá-Santarém. Até 1974 apenas 6 (seis) mil famílias haviam se assentado nessa região. Na perspectiva de Higa (2005), o governo federal estimulou a instalação maciça de projetos de "colonização empresarial" (agropecuários, agroindustriais e de mineração) e de colonização privada, concentrando, nas décadas de 1970/1980, 243 projetos empresariais.

Os programas governamentais que produziram impactos econômicos e socioambientais em Mato Grosso foram: o Programa de Redistribuição de Terras e Estímulos à Agroindústria do Norte e Nordeste (PROTERRA) e o Programa de Desenvolvimento do Centro-Oeste (PRODOESTE), instituídos em 1971. No PROTERRA, os recursos foram destinados à abertura de linhas de crédito agrícola, de infraestrutura básica e de aquisição de insumos e equipamentos para a agroindústria. Financiou-se a implantação de projetos privados de colonização nas regiões centro-norte e leste do Estado. O PRODOESTE objetivou a interligação dos grandes eixos rodoviários para canalizar o escoamento da produção até os principais centros de comercialização e, com isso, beneficiou, principalmente, a região sul do Estado, que hoje compreende o estado de Mato Grosso do Sul (MORENO, 2005).

No âmbito dos Planos Nacional de Desenvolvimento (PNDs I e II) destacaram-se os programas integrados de desenvolvimento regional: Programa de Polos Agropecuários e Agrominerais da Amazônia (POLOAMAZÔNIA), Programa para o Desenvolvimento dos Cerrados (POLOCENTRO) e Programa de Desenvolvimento do Pantanal (PRODEPAN), os quais, geridos por instituições públicas, nas esferas federal, estadual e municipal, resultaram em impactos econômicos, sociais, ambientais e contribuíram para a reordenação do espaço territorial do estado de Mato Grosso.

Pela perspectiva de Souza (2002), o POLOAMAZÔNIA (1974) promoveu a ocupação e desenvolvimento de 15 áreas da Amazônia Legal, além de apoiar projetos de iniciativa privada nos setores de pavimentação, eletrificação, colonização e pesquisa. Vale lembrar que, pela Lei 1.806 de 06.01.1953, a Amazônia Brasileira passou a ser chamada de
Amazônia Legal em decorrência de conceito político, pela necessidade do governo de planejar e promover o desenvolvimento da região (IPEA, 2012). O POLOCENTRO (1975) teve o objetivo de conceder investimentos para a instalação de infraestrutura necessária ao aproveitamento dos cerrados do Centro-Oeste. Para Higa (2005), o PRODEOPAN previu a regularização dos cursos d'água com vistas ao controle de enchentes, ao saneamento básico, à expansão de oferta de energia, dentre outros.

Com os focos de investimentos delineados acima, o Mato Grosso tornou-se objeto do planejamento federal por meio da política de ocupação implementada com a construção de Brasília e investimentos em infraestrutura na região Centro-Oeste. Os investimentos em infraestrutura, decorrentes do Plano de Metas, proporcionou uma maior integração econômica, especialmente da região nordeste de Mato Grosso. Para Moreno (2005), a construção das rodovias, evidenciada na Figura 1, contribuiu para que a região se consolidasse como área de influência socioeconômica.

Durante os governos militares (1964-1985), o Mato Grosso se beneficiou duplamente com a atuação das políticas e ações da Superintendência do Desenvolvimento da Amazônia (SUDAM) e da Superintendência do Desenvolvimento do Centro-Oeste (SUDECO). Os benefícios influenciaram no reordenamento do espaço territorial do Estado. A SUDAM e a SUDECO objetivaram coordenar e concentrar a ação governamental de planejamento e implantação de infraestrutura socioeconômica e institucional nas regiões Norte e Centro-Oeste, respectivamente (HIGA, 2005).

Na década de 1970, foi criado o Instituto Nacional de Colonização e da Reforma Agrária (INCRA) que se tornou o responsável pela demarcação dos espaços vazios para a colonização pública, estratificação fundiária e assentamentos em vários núcleos de colonização oficiais. Segundo Teixeira (2006), entre 1970 e 1974, o INCRA priorizou o assentamento de colonos pobres de Mato Grosso, conforme proposta do projeto POLONOROESTE, para atender aos seguintes objetivos: econômico (aumentar a produção de alimentos para o mercado interno e para a exportação); demográfico (frear o êxodo rural e reorientar para a Amazônia o fluxo que se dirigia para as metrópoles do Sudeste); social (diminuir as 
tensões sociais provocadas pelo latifúndio no Nordeste e pelo minifúndio no Sul do país).

A atuação do INCRA em projetos de colonização nas décadas de 1970 e 1980 se deu na mesorregião Norte Mato-Grossense, em três grandes ações (MORENO, 2005):

1. Projeto de Assentamento Rápido (PAR) - desenvolvido com o apoio do estado e municípios, em áreas que possuíam o mínimo de infraestrutura. Teve a finalidade de eliminar os focos de tensão social nas áreas selecionadas. O INCRA delimitou, demarcou e forneceu a titulação dos lotes que, em média, possuíam 50 hectares. Foram contemplados dois núcleos em Mato Grosso: o primeiro, na região onde hoje estão localizadas as cidades de Rondolândia, Aripuanã e Colniza. O segundo, nas atuais cidades de Colíder e Nova Canaã do Norte;

2. Projeto de Ação Conjunta (PAC) - consistiu numa ação conjunta do INCRA e de uma cooperativa. O primeiro colocava infraestrutura básica, e a cooperativa respondia pela administração e manutenção do projeto, com oferta de assistência técnica e financeira. Foram contemplados os municípios de Guarantã do Norte, Alta Floresta e Nobres;

3. Projeto Especial de Assentamento (PEA) consistiu em ações emergenciais para atender populações removidas compulsoriamente, por decisão do governo federal, de áreas de conflito. O INCRA foi responsável pelo loteamento, infraestrutura e administração técnico-financeira. Inicialmente, o projeto estava destinado aos "sem- terras", do acampamento da Encruzilhada do Natalino, em Ronda Alta (RS). Foi implantado na cidade de Lucas do Rio Verde.

Em paralelo às ações do governo federal, em 1975, o governo de Mato Grosso criou o Instituto de Terras do Estado de Mato Grosso (INTERMAT), com objetivo de planejar e executar as políticas agrária e fundiária. Segundo Moreno (2005), na tentativa de minimizar e erradicar os conflitos na região. Foram beneficiadas 9.203 (nove mil, duzentas e três) famílias, mediante os seguintes projetos:
1. Assentamentos Convencionais - destinados a trabalhadores rurais sem-terra;

2. Assentamentos de Comunidades Tradicionais - revitalização de comunidades originadas de ocupações antigas, com tradição agrícola e carente de recursos;

3. Vilas Rurais - localizadas no entorno dos centros urbanos para atender trabalhadores desempregados acima de 45 (quarenta e cinco) anos e com aptidão para trabalho agrícola.

Além de identificar as áreas devolutas e incorporá-las ao patrimônio do estado, o INTERMAT também teve o intuito de regularizar as já ocupadas, de maneira a eliminar conflitos sociais provocados pelo uso e posse de terra (HIGA, 2005). Neste aspecto, vale lembrar o que Araújo Neto e Leite (2005) escreveram sobre os espaços antes da ação política do Estado Nacional. Para eles, ao final da década de 1960, a região Centro-Oeste, especificamente Mato Grosso, apresentava dois tipos de estrutura espacial consolidada: áreas de povoamento estabilizadas e espaços estruturados pela pecuária modernizada.

Neles, os proprietários de terras (pecuaristas) foram beneficiados pela infraestrutura implantada na região e consequente valorização das terras, o que favoreceu ao acúmulo de capital via arrendamento ou venda da terra, sem que necessitassem comercializar sua produção. Com isso, fez surgir dois tipos de produtores: de um lado, os capitalizados (provenientes do Sul, que reproduziram o capital trazido, transformando-se em empresários rurais pelo crédito e infraestruturas disponíveis); e, de outro, os produtores descapitalizados e pequenos produtores (sem crédito, que tiveram que vender suas terras ou posses, o que favoreceu ao latifúndio).

Nesse espaço produtivo, há áreas destinadas à atuação da pecuária extensiva, do extrativismo vegetal, da garimpagem de ouro e de diamantes, as quais são pouco povoadas e distantes dos centros urbanos. Além disso, tivemos as "áreas de fronteira agrícola [que foram] invadidas e intermediadas por grileiros, com expulsão de posseiros, surgindo os conflitos de terras" (ARAÚJO NETO; LEITE, 2005, p. 211).

Embora os programas oficiais de colonização gerassem grande afluência de migrantes, os resultados ficaram aquém dos objetivos do povoamento, diversificação e expansão da pequena produção. 
Em parte, porque o governo estadual não proporcionou assistência técnica e financeira para os produtores, o que favoreceu a atuação de empresas particulares nas negociações e acordos com bases em interesses de grupos econômicos ou políticos. A maioria dos contratos não foi cumprida, principalmente nos aspectos de "infraestrutura física e social, como medição e demarcação de lotes, abertura de estradas, educação e saúde" (MORENO, 2005, p. 60).

Inúmeras reestruturações ocorreram no Mato Grosso em face de sua grande extensão territorial. Em 1977 houve a divisão do estado criando, a partir dessa separação, o Mato Grosso do Sul (HIGA, 2005). Este último foi incorporado ao mercado nacional com produção e abastecimento de alimentos destinados às regiões Sul e Sudeste. A partir do desmembramento, o Mato Grosso passou a fazer parte da área da Amazônia Legal e, em virtude disto, passou a usufruir os estímulos dos programas criados para as regiões da Amazônia e do Centro-Oeste.

Importa reconhecer que o fracionamento de Mato Grosso, ocorrido em 1977, representou um marco no processo de ocupação e crescimento de novos territórios, "com incentivos fiscais, programas de apoio, melhoria e expansão em infraestrutura básica, geraram estímulos às frentes agropecuárias pioneiras" (HIGA, 2005, p.90). Seus efeitos foram sentidos no crescimento e interiorização da população e da economia, na intensa urbanização e na criação de novos municípios.

Inicialmente, a ocupação e urbanização concentraram-se no sul de Mato Grosso, em cidades próximas a Cuiabá, sua capital. A partir da década de 1980, explicitou-se a necessidade de intensificar a ocupação das regiões do Médio-Norte e do Norte Mato-Grossense como forma de recompor parte da renda perdida com a divisão. O INCRA e a SUDAM aumentaram sua interferência como planejadores e financiadores do desenvolvimento agropecuário na região e estabeleceram grandes empreendimentos produtores de commodities agrícolas a oeste do Parque Nacional do Xingu (criado em 1961), no Médio-Norte Mato-Grossense.

As finanças de Mato Grosso foram restabelecidas com a venda de centenas de milhares de hectares para os empreendimentos de colonização privada, devidamente autorizados pelo governo federal. As colonizadoras privadas foram: Colonizadora FELIZ
(Sorriso); SINOP (Vera, Cláudia, Santa Carmen e Sinop); MAIKÁ (Marcelândia); LÍDER (Colíder, Nova Canaã do Norte) e INDECO (Alta Floresta, Paranaíta, Apiacás). Todas atuaram na mesorregião Norte Mato-Grossense entre as décadas de 1980 até 2000. A justificativa dada pelos governos estadual e federal para o fortalecimento das colonizações privadas era de que seria impraticável a colonização pela via da gestão pública, baseada em pequenos e médios proprietários (VILLAR, NÉDÉLEC, FERREIRA, at al, 2005; TEIXEIRA, 2006). Fomentaram-se, com isso, os projetos de colonização privada através de créditos e incentivos fiscais. Segundo Souza (2004, p. 98), a colonização privada foi definida como "a nova maneira de promover o aproveitamento econômico da terra".

Atualmente, os entes federados permanecem realizando investimentos para que se possa dar o desenvolvimento regional. $\mathrm{O}$ instrumento adotado para esse fim são as políticas públicas estruturadas nos eixos: infraestrutura logística (rodovias, ferrovias, portos, aeroportos e hidrovias), infraestrutura energética (geração e transmissão de energia elétrica, petróleo, gás natural e combustível renovável) e infraestrutura social e urbana (saneamento, habitação, transporte urbano e recursos hídricos). Neles, vê-se o incentivo ao crescimento da rede urbana de Mato Grosso a partir do século XXI.

\section{Metodologia}

Para identificar as modificações do espaço, via a ocupação urbana, foram utilizados - para o exercício de análise exploratória - os dados dos Censos do IBGE (de 1970 a 2010) dos 55 municípios da mesorregião Norte Mato-Grossense, que compreende cerca de $50 \%$ de seu território, sendo formado por $141 \mathrm{mu}-$ nicípios e possuindo uma área de $903.329,700 \mathrm{~km}^{2}$ (IBGE, 2010). A organização político-administrativa de Mato Grosso foi definida em 1977, quando da divisão territorial de Mato Grosso do Sul (MORENO; HIGA, 2005).

Para a fundamentação, utilizou-se a pesquisa bibliográfica e documental para identificar e analisar as políticas de ocupação e urbanização do território. Para a obtenção de dados econômicos do estado foram usadas fontes secundárias da Secretaria de Planejamento do Estado de Mato Grosso (SEPLAN-MT) 
e do Instituto Brasileiro de Geografia e Estatística (IBGE). Os mapas das rodovias que cortam o estado foram montados a partir de dados do Ministério de Transportes.

A delimitação da área de estudo foi definida a partir da classificação das Mesorregiões Geográficas de Mato Grosso, elaborada pelo IBGE (2011). As mesorregiões são tomadas como universo de análise definidas com base nas dimensões do processo social, no quadro natural, na rede de comunicação e nos lugares na articulação espacial. São constituídas por conjuntos de municípios próximos, que apresentam especificidades na organização do espaço, dentre as quais: a estrutura de produção, as relações sociais e econômicas.
O Mato Grosso divide-se em cinco mesorregiões geográficas (Figura 2):

1. Centro-Sul: formada por 17 municípios, agrupados em quatro microrregiões;

2. Nordeste: formada por 25 municípios, agrupados em três microrregiões;

3. Norte: formada por 55 municípios, agrupados em oito microrregiões;

4. Sudeste: formada por 22 municípios, agrupados em quatro microrregiões;

5. Sudoeste: composta por 22 municípios, agrupados em três microrregiões.

Figura 2 - Mesorregiões de Mato Grosso

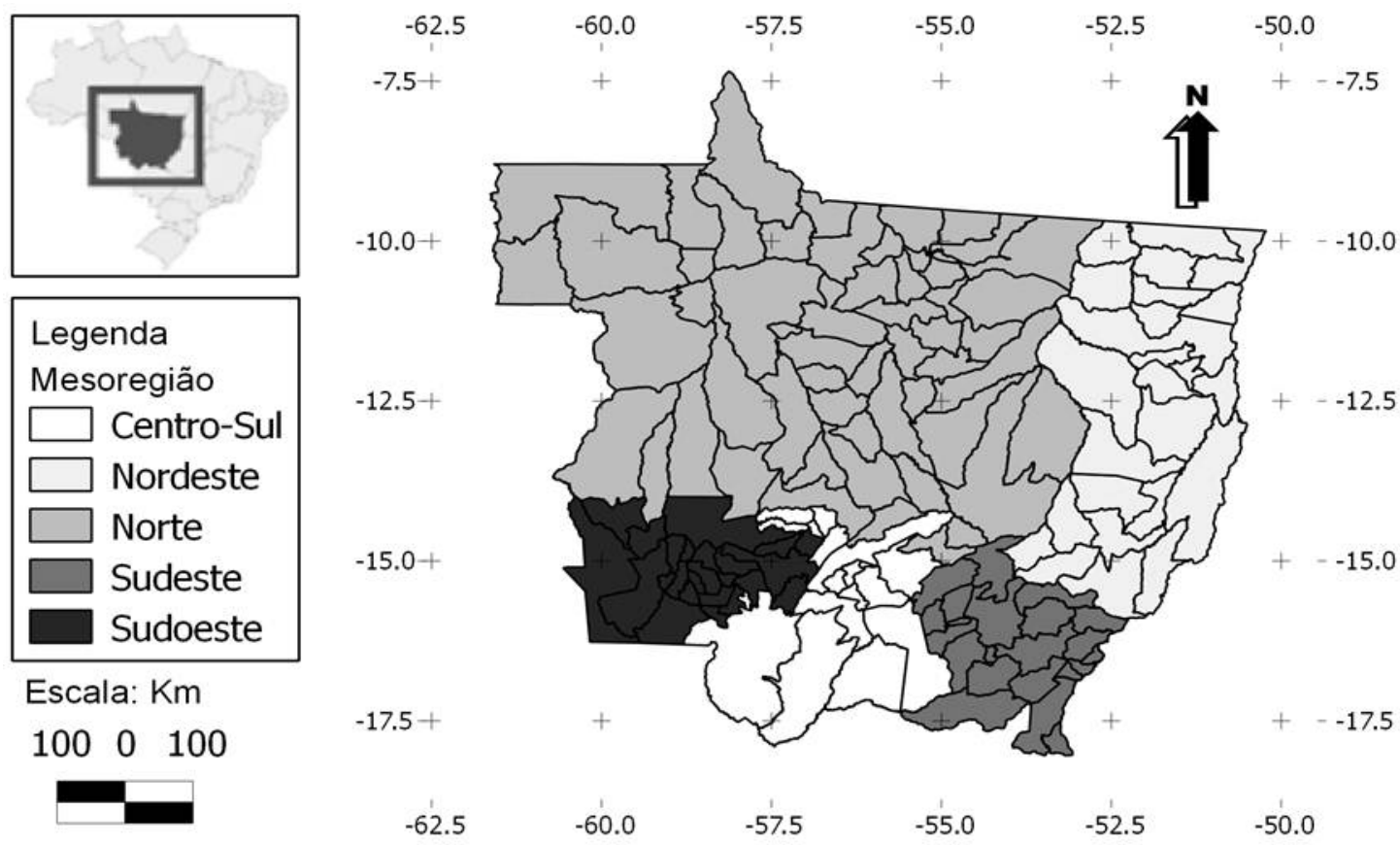

Fonte: Dados da Pesquisa (2011).

O interesse por estudar a mesorregião Norte Mato-Grossense se deu pelo fato de seus municípios guardarem entre si um crescimento semelhante, tanto no processo de colonização e urbanização, quanto no social e econômico. Nela estão compreendidas 8 das 22 microrregiões do estado, segundo o IBGE, e 6 regiões das 12 regiões de planejamento do governo de Mato Grosso (SEPLAN-MT, 2007). Quando se discute a participação desta mesorregião, está se valendo de fatores que influenciam mais da metade do território de Mato Grosso.

\section{Resultados e Discussão \\ A urbanização na mesorregião Norte Mato- -Grossense}

Desde o final do século XIX acentuou-se o crescimento das cidades em razão de a principal base produtiva estar situada no sistema industrial. A população mundial nas cidades saiu de 900 milhões de habitantes e chegou ao ano de 2000 com, aproximadamente, 3.000.000.000 habitantes (NETO, 2005, p.120). Para Santos (2009), o nível de urbanização, 
seu desenho e as manifestações populares são realidades que necessitam ser estudas sob prisma econômico, político, sociocultural e nas formas de uso do território.

A urbanização é um processo social que impulsiona a liberação de indivíduos das atividades de plantio e coleta de alimentos (SANDRONI, 1999). Seu incremento se deu quando a produção regular de excedente agrícola permitiu que parcelas da população se dedicassem, exclusivamente, às práticas artesanais, comerciais, administrativas, militares, políticas ou intelectuais. Esse fenômeno, no Brasil, acentuou-se, generalizadamente, a partir do "terceiro terço do século XX” (SANTOS, 2009, p. 6) e se avolumou a partir do momento em que a residência dos trabalhadores agrícolas tornou-se cada vez mais urbana.

No Mato Grosso a urbanização refletiu as inúmeras contradições (econômicas, sociais, político-culturais) no seu espaço territorial. Elas estão evidenciadas na desigualdade social, na estratificação social e na produção setorizada do espaço urbano. Via de regra, as cidades que apresentaram crescimento demográfico acelerado também tiveram crescimento espacial e social desordenado, crescimento econômico desigual e forte estratificação social. Parcelas da população com alto poder aquisitivo e elevado padrão social influenciaram e definiram os rumos do crescimento. E, ao contrário, as camadas pobres da população vivem em condições precárias de moradias, sem infraestrutura urbana básica (SANTOS, 2009). Nessa perspectiva, os processos de urbanização e da formação econômico-social de Mato Grosso não foram diferenciados.

A formação do espaço urbano em Mato Grosso teve origem na primeira metade do século XVIII, ao sul e oeste do estado, com a constituição dos núcleos de Chapada dos Guimarães, Cáceres, Diamantino, Rosário Oeste, Santo Antônio de Leverger e Barão do Melgaço (NETO, 2005). Tais núcleos tornaram-se cidades e vilas e, 200 anos depois, ainda apresentam pequeno crescimento urbano, em função das dificuldades de acesso, dadas as limitações de transportes (Figura 1).

No caso da mesorregião Norte Mato-Grossense, o crescimento urbano das cidades ocorreu conforme a ocupação do território do estado e foi se polarizando, do sul para o norte, ao longo das décadas de
1970 a 2010, comprovando o que Santos (2009) afirmava sobre os espaços urbanos e suas características peculiares, como origem da população, sua cultura e a busca por novas fontes de renda.

Para compreender a urbanização da mesorregião Norte Mato-Grossense é preciso atentar para o rápido aumento do número de municípios no estado, os quais tiveram suas áreas urbanas planejadas pelas colonizadoras privadas. Cabe mencionar o caso do município de Sinop (1971), onde a Colonizadora Sociedade Imobiliária Noroeste do Paraná (SINOP) montou uma estrutura mista de colonização que combinava atividade agropecuária e indústria de transformação. A estrutura agropecuária constava de seções que se transformaram nos municípios de Vera, Sinop, Santa Carmem e Cláudia. Cada município teria um centro populacional. Em volta do centro, as chácaras e, mais ao longe, os lotes rurais. Contudo, a localização da estrutura industrial foi projetada para ter a sede em Sinop por estar às margens da BR-163 (MORENO, 2005).

Até a década de 1970, a mesorregião Norte Mato-Grossense não sofreu a ocupação territorial. Não haviam sido implantadas políticas/programas governamentais para a integração e a ocupação territorial. Até então, havia 4 (quatro) municípios (Aripuanã, Diamantino, Nobres e Porto dos Gaúchos) que, juntos, possuíam 14.195 habitantes. Destes, apenas 3.168 habitantes estavam na área urbana dos municípios (NETO, 2005).

Na década de 1980, segundo o IBGE (1980), ocupavam esta mesorregião 164.474 habitantes. Deles, apenas 50.561 residiam na área urbana e estavam distribuídos pelas 10 (dez) cidades existentes. Os 113.913 habitantes residentes nas áreas rurais encontravam-se dispersos em 482.748,774 km², com densidade demográfica rural em $0,26 \mathrm{hab} . / \mathrm{km}^{2}$. Destas, apenas 2 (dois) municípios possuíam mais de 15.000 habitantes: Alta Floresta (16.375 habitantes) e Colíder (30.848 habitantes).

Ainda nos anos de 1980 começou a haver a mobilidade da população no território, inicialmente no limite das áreas rurais para as urbanas dos municípios que estavam se formando a partir do desmembramento de outros. A atratividade da população deveu-se à facilidade de acesso às terras, com oferta a preços baixos e a possibilidade de exploração via atividades econômicas primárias, como a exploração 
de madeira, minérios e pecuária extensiva e agricultura de precisão.

Somente na década de 1990 formaram-se os núcleos urbanos mais densos, como Juara, Juína, Peixoto de Azevedo e Alta Floresta, concentradas no centro-norte da mesorregião. Essas cidades se constituíram como centros de serviços básicos para a população que atuava em atividades fundamentalmente rurais. A mesorregião Norte possuía 530.699 habitantes, sendo 220.860 habitantes na área rural e 309.839 habitantes na área urbana, distribuídos em 33 municípios. Aqui se constata a reversão da população do rural para o urbano, caracterizando o êxodo rural. Desde então, formaram-se as cidades-polos (Alta Floresta, Juína, Peixoto de Azevedo e Sinop) com mais de 25.000 habitantes (MORENO, 2005), onde se observa uma maior dispersão da população no território, de forma a homogeneizar a ocupação do espaço nas áreas rurais e concentrar mais as pessoas nas áreas urbanas.

No início do século XXI ocorreu a maior polarização e distribuição populacional no território, por meio de incentivos para as cidades-polos que, com o crescimento na oferta e consolidação da infraestrutura básica na área urbana, culminou no fortalecimento dos municípios de Colniza, Campo Novo do Parecis, Nova Mutum, Lucas do Rio Verde e Sinop. Esse cenário de expansão da área urbana foi viabilizado pelos processos e dinamismo dos setores econômico, primário e secundário, a centralização no agronegócio via expansão da soja, a intensificação da agroindústria, com implantação de frigoríficos de aves, suínos e bovinos e a indústria canavieira. Em 2000, segundo o censo populacional (IBGE, 2010), a população urbana contou com 494.634 habitantes e a população rural em 298.926 habitantes, totalizando 793.560 pessoas e uma densidade demográfica total de $1,64 \mathrm{hab} / \mathrm{km}^{2}$.

Vale lembrar que a implementação de infraestrutura básica nos municípios, como saneamento, asfalto e energia elétrica, foi lenta no decorrer do tempo. As cidades mais antigas, emancipadas politicamente, via de regra, tiveram esses serviços mais desenvolvidos, tornando-se mais atrativas para a população em movimento, tanto na migração interna como a imigração.

Chegou-se aos anos 2000 e se constatou que a forma planejada pelas colonizadoras para ocupar a área de forma racional, idealizada na década de 1970, não se confirmou. Tal aspecto foi detectado pelo estudo de Oliveira et al. (2009), segundo o qual o processo de ocupação dos espaços vazios acontece pela combinação de esforços públicos e privados, na realidade em tela isto tem se ampliado nas últimas décadas. No caso de Mato Grosso, as cidades de Cláudia, Santa Carmem e Vera, antes idealizadas como polos urbanos, só conseguiram manter em sua área urbana 18.877 habitantes; enquanto o município de Sinop que, a princípio, era para estar como polo industrial, tornou-se centro em serviços, integrado por 93.735 habitantes na área urbana, conforme dados do último censo (IBGE, 2010).

Dentre os fatores que podem explicar a concentração urbana no município de Sinop está o traçado da rodovia BR 163, que corta a cidade no sentido norte-sul, facilitando o escoamento da produção regional, o que propiciou o adensamento populacional no seu entorno. Essa mesma característica de urbanização fica evidenciada nos municípios de Alta Floresta (42.787 habitantes), Guarantã do Norte (23.917 habitantes), Lucas do Rio Verde (42.438 habitantes), Nova Mutum (25.858 habitantes) e Sorriso (58.363 habitantes). Todos à margem da BR 163, conforme demostrado na Figura 1.

Em 2010, segundo o censo do IBGE, a população da mesorregião Norte totalizou 941.996 habitantes e o estado com 2.954.625 habitantes. Considerando que esta mesorregião possui $53,77 \%$ do território estadual, significa que quase um milhão de pessoas reside neste espaço. Tem-se uma densidade demográfica rural de $0,51 \mathrm{hab} . / \mathrm{km}^{2}$ e a urbana de 1,44 hab. $/ \mathrm{km}^{2}$.

Segundo o Censo 2010 (IBGE, 2010), no período, $15,65 \%$ da população brasileira vivia na área rural e $84,35 \%$ na área urbana. Dentre os 19 municípios brasileiros que dobraram sua população, 3 deles integram o Mato Grosso, Sapezal (129,85\%), Nova Mutum (113,48\%) e Juruena (106,85\%). Mesmo com o crescimento da população rural em toda mesorregião, até 1991 o Norte Mato-Grossense era considerado um "vazio demográfico", dada a dificuldade de acesso por falta de rodovias para servir de corredor à migração e ao escoamento de produtos.

A partir dos anos de 2000, com a chegada da agricultura de precisão, principalmente na produção da soja, houve maior concentração de terras no es- 
paço rural em mãos do menor número de pessoas. Concomitantemente, a rede urbana se fortaleceu. Os municípios que tiveram crescimento mais significativo de sua população urbana foram aqueles que, efetivamente, ofertaram uma gama maior de serviços essenciais, como escolas, hospitais, água, luz e asfalto.
A Figura 3 abaixo representa os 55 municípios da mesorregião Norte Mato-Grossense que possuem domicílios com os serviços de iluminação elétrica e água canalizada. Nesta figura, só estão representados dois serviços porque o de instalações sanitárias, até o ano de 2000, era inexistente nesses municípios.

Figura 3 - Iluminação elétrica e água canalizada - Mesorregião Norte Mato-Grossense - 1980 a 2000

\section{Mesorregião Norte Mato-grossense}

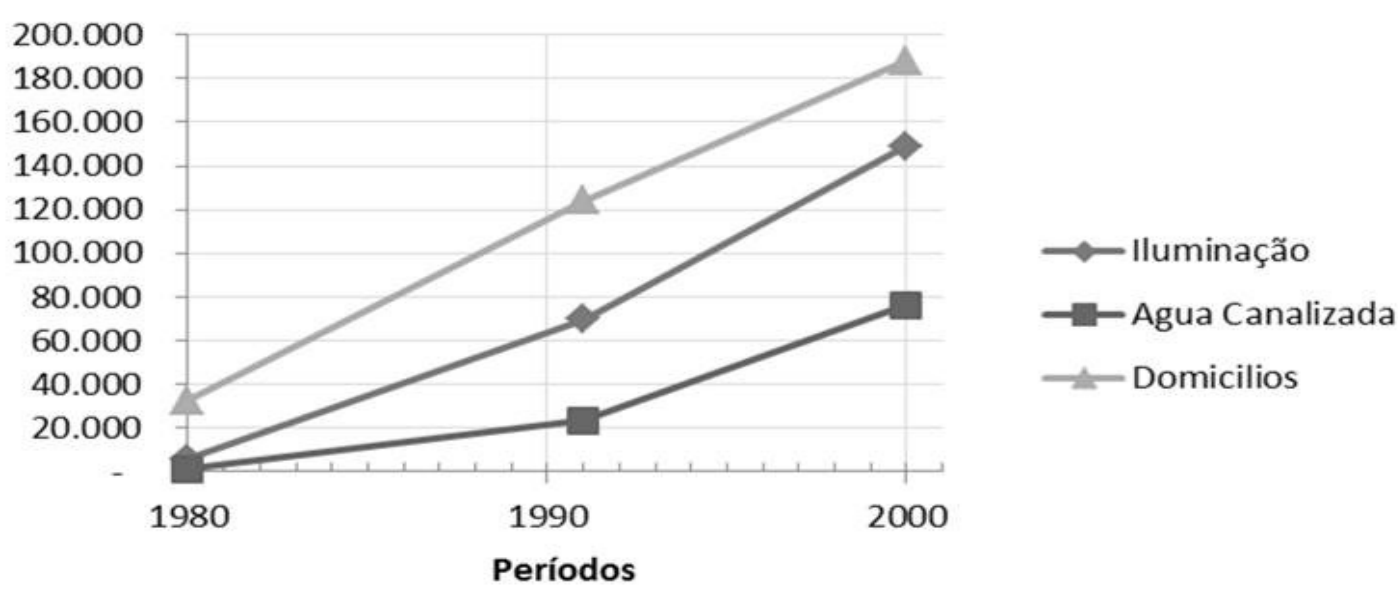

Fonte: Adaptação dos Censos do IBGE (1980, 1991, 2000).

$\mathrm{Na}$ Tabela 1 estão representados os serviços citados e seu crescimento percentual, no decorrer das décadas estudadas. Observa-se que a iluminação elétrica chegou primeiro aos domicílios Norte-Mato-Grossenses, os serviços de água canalizada. Entretanto, as instalações sanitárias aparecem em grau reduzido nos lares desta mesorregião, pois este serviço só passam a ocorrer na década de 2000 e, mesmo assim, representa um pouco mais de $0,50 \%$ dos lares. Supõe-se que se trata de lares mais antigos, instalados na década de 1980 e que chegaram ao início do século XXI melhor estruturados. Isto é evidenciado nos municípios de Alta Floresta, Juara, Peixoto de Azevedo, Sinop e Colíder, fundados entre as décadas de 1970 e final de 1980 (SUS-MT, 2012).
Tabela 1 - Percentual de domicílios com iluminação, água canalizada e instalações elétricas - Mesorregião Norte Mato-Grossense - 1980 a 2000.

\begin{tabular}{llll}
\hline & $\mathbf{1 9 8 0}$ & $\mathbf{1 9 9 1}$ & $\mathbf{2 0 0 0}$ \\
\hline Domicílios & $100,00 \%$ & $100,00 \%$ & $100,00 \%$ \\
Iluminação & $18,06 \%$ & $56,19 \%$ & $79,35 \%$ \\
Agua Canalizada & $3,52 \%$ & $18,92 \%$ & $40,68 \%$ \\
Inst. Sanitárias & - & - & $0,61 \%$ \\
\hline
\end{tabular}

Fonte: Adaptação dos Censos do IBGE (1980, 1991, 2000).

A Figura 4 mostra o crescimento, em percentual, ao longo das décadas de 1980 a 2000, nos domicílios dos 55 municípios da mesorregião Norte Mato-Grossense, dos serviços de iluminação e de água canalizada. 
Figura 4 - Crescimento em percentual, dos serviços de iluminação e água canalizada nos domicílios Mesorregião Norte Mato-Grossense - 1980 a 2000.

\section{Mesorregião Norte Mato-grossense}

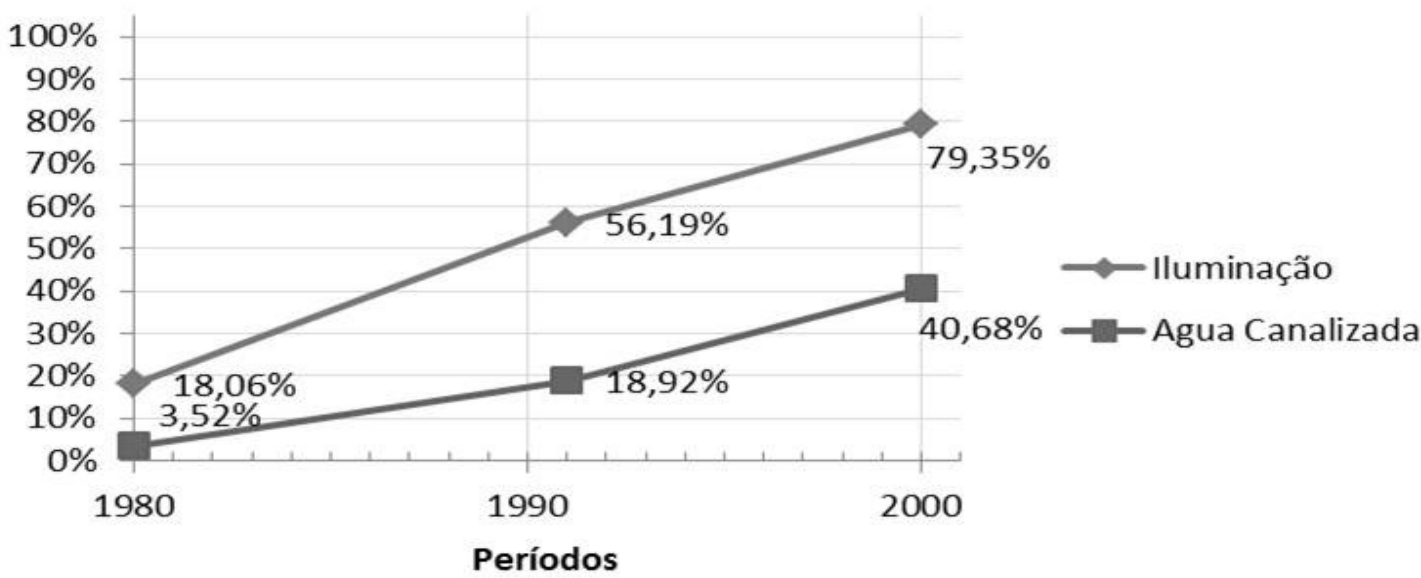

Fonte: Adaptação dos Censos do IBGE (1980, 1991, 2000).

Ao correlacionar a expansão dos serviços básicos de infraestrutura urbana com o tamanho da população urbana na maioria dos municípios da mesorregião norte indaga-se: o que é urbano neste território? A oferta de tais serviços é irrisória, se considerarmos o número de pessoas que tem domicílio no perímetro urbano das cidades e o tamanho da área de cada município dessa região. Como exemplo desse fato, citam-se as três cidades de Mato Grosso consideradas pelo IBGE (2010) como as que tiveram a população dobrada na última década (mas que possuem uma baixa densidade populacional), conforme disposto abaixo:

Tabela 2 - Densidade demográfica, área e população das cidades-destaque - Mesorregião Norte Mato-Grossense - 2010.

\begin{tabular}{llllll}
\hline Cidades & Área $\left(\mathbf{k m}^{\mathbf{2}}\right)$ & Pop. Urbana & Pop. Rural & Pop. total & Hab./km $^{\mathbf{2}}$ \\
\hline Sapezal & 13.598 & 15.120 & 2.920 & 18.080 & 1,33 \\
Nova Mutum & $9.537,923$ & 25.858 & 5.775 & 31.633 & 3,31 \\
Juruena & $3.190,476$ & 6.801 & 4.468 & 11.269 & 3,50 \\
Sinop* & $3.194,339$ & 93.735 & 19.347 & 113.082 & 35,40 \\
\hline
\end{tabular}

Fonte: IBGE (2010).

$\left.{ }^{*}\right)$ Única cidade da mesorregião Norte Mato-grossense, em 2010, com mais de 100.000 habitantes.

As cidades com maior concentração urbana são as que, na última década, tiveram os seguintes fatores de atratividade: Sapezal teve o incremento de $129,85 \%$ na população em razão da instalação de usinas de açúcar e destilarias de etanol; Nova $\mathrm{Mu}-$ tum com crescimento populacional de 113,48\%, em função da instalação de frigoríficos de suínos e aves; Juruena que cresceu $106,85 \%$ pela instalação de indústria madeireira, que ocupa $60 \%$ da mão de obra da área urbana (PREFEITURA MUNICIPAL DE JURUENA, 2011); e o município de Sinop, com 113.082 habitantes, tem $82,89 \%$ de sua população na área urbana, polo regional no setor terciário, com a prestação de serviços de saúde, educação e serviços públicos nas esferas estadual e federal, como Polícia Federal, EMBRAPA, instalação da base do Exército, Marinha e Aeronáutica, dentre outros.

\section{Conclusões}

O estudo evidenciou o papel que tiveram as políticas públicas no estado de Mato Grosso como mecanismo fomentador de infraestrutura básica e, ao mesmo tempo, para o fomento do incentivo ao desenvolvimento de atividades econômicas, atratividade populacional e adensamento territorial. 
Tornou-se mais claro que a atratividade de pessoas para um município e a ocupação da área urbana só acontecem quando os fatores de renda, infraestrutura básica e acesso a serviços são oferecidos à população. A partir da implementação de políticas públicas que trataram desde a oferta de terras a preços acessíveis e fomento para desenvolvimento de atividades econômicas, como na agropecuária, propiciou-se o crescimento de infraestrutura básica, o que contribuiu para a melhoria da qualidade de vida. Com isso, a população concentra-se nas cidades a despeito de permanecer atuando nos setores primários, como acontece na maioria das 55 cidades da mesorregião Norte Mato-Grossense.

Com a implementação de condições de infraestrutura básica para o fortalecimento de atividades econômicas, principalmente as secundárias e terciárias, demostradas nas Figuras 1, 2 e 3, percebe-se a forma como se processa a articulação da área rural do município com seu núcleo de trabalho e renda, provenientes das atividades primárias.

O papel dos governos federal, estadual e municipal, através das políticas públicas, foi fundamental para o surgimento e fortalecimento de núcleos de povoamento que se transformaram em cidades.

A oferta de serviços urbanos, como água encanada, energia elétrica e asfalto, tornaram esses núcleos urbanos centros de referência, o que acabou atraindo populações do Sul e Sudeste do país, favorecendo o crescimento de atividades secundárias e terciárias na mesorregião Norte Mato-Grossense, fortalecidas pela renda oriunda de atividades agropecuárias e extrativistas.

\section{Referências Bibliográficas:}

ALVES, L. R.; FERRERA DE LIMA, J.; SOUZA, C. C. G. de. Distribuição espacial das atividades econômicas entre as mesorregiões do Brasil: 1970 e 2000. In: Anais...: VIII ENABER. São Paulo: s.n. Setembro de 2009.

ARAÚJONETO, M.D. de;LEITE, C.M.C. Desenvolvimento socioeconômico no contexto da região Centro-Oeste. In: MORENO, G.; HIGA, C. S. (Orgs.). Geografia de Mato Grosso. Cuiabá: Entrelinhas, 2005. p. 145-155.

BECHER, B. Revisão das políticas de ocupação da Amazônia: é possível identificar modelos para projetar cenários? Revista Parcerias Estratégicas: CGEE, $\mathrm{n}^{\mathrm{o}}$ 12, setembro de 2001, p. 135-159.
BOEIRA, S.; SANTOS, A. C. B. dos; SANTOS, A. G. dos. Estatuto da Cidade: aspectos epistemológicos, sociopolíticos e jurídicos. Revista de Administração Pública (RAP). Rio de Janeiro: EBAPE/FGV. Vol. 43, n.3, mai/jun. 2009, p. 695712.

CACCIA BAVA, S. A produção da agenda social: uma discussão sobre contextos e conceitos. Fundação Getúlio Vargas. Cadernos Gestão Pública e Cidadania. São Paulo: FGV. Vol. 31, agosto de 2003, p. 01-34.

CORREA R. L. Região e organização espacial. 7. ed. São Paulo: Ática, 2002.

HARVEY, D. Condição pós-moderna. 17. ed. São Paulo: Loyola, 2007.

HIGA, T. C. S. Processo de ocupação e formação territorial. In: MORENO, G.; HIGA, C. S. (Orgs.). Geografia de Mato Grosso: território, sociedade, ambiente. Cuiabá: Entrelinhas, 2005.p.90-102.

INSTITUTO DE PESQUISA ECONÔMICA E AGROPECUÁRIA (IPEA). O que é Amazônia Legal? Disponível em: <http://www.ipea.gov.br/desafios/index. php?option $=$ com_content $\&$ view $=$ article $\&$ id $=2154$ : catid $=28$ \&Itemid=23>. Acesso em: 14 jun.2012.

INSTITUTO BRASILEIRO DE GEOGRAFIA E ESTATÍSTICA (IBGE). Censo Demográfico 1980: regiões Norte, Nordeste e Centro-Oeste-Microdados do universo. Disponível em: $\quad<$ http://www.ibge.gov.br/lojavirtual/ fichatecnica.php?codigoproduto $=4777 \&$ midia $=>$. Acesso em: 01 dez. 2011.

Censo Demográfico 2010. Disponível em: $<\mathrm{http} / /$ biblioteca.ibge.gov.br/>. Acesso em: 06 ago. 2011.

Divisão regional. Disponível em: $<\mathrm{http} / / \mathrm{www}$. ibge.gov.br/home/geociencias/ geografia/default_div_int. shtm>. Acesso em: 11 ago. 2011.

Sala de imprensa. Censo 2010. Disponível em: $\overline{<\mathrm{http}: / / w w w . i b g e . g o v \cdot b r / h o m e / p r e s i d e n c i a / n o t i c i a s / n o t i c i a}$ visualiza.php?id_noticia $=1766$ novembro/2011>. Acesso em: 29 ago. 2011.

LEGISLAÇÃO. Lei 1.806, de 06.01.1953. Legislação sobre a criação da Amazônia Legal. Disponível em: <http://www. ada.gov.br/index.php?view $=$ article \&catid $=61 \% 3$ Aamazonia lega $1 \& \mathrm{id}=43 \% 3$ Aamazonialegallegislacao \&format $=$ pdf\&o ption=com_content\&Itemid=36>. Acesso em: 14 ago. 2011.

MAFRA, L. A. S. Gestão de políticas sociais: a importância das articulações institucionais e setoriais em programas de segurança alimentar e nutricional. In: CADERNOS EBAPE.BR. Rio de Janeiro: FGV. v. 7. $\mathrm{n}^{\circ}$ 1. Art 3. mar. 2009, p.35-49.

MESO NORTE. Mesorregião Norte Mato-Grossense. Disponível em: <http://mesonorte.b logspot.com/2007/10/ mesorregio-do-norte-mato-grossense.html $>$. Acesso em: 11 jun. 2011. 
MORENO, G. Políticas e estratégias de ocupação. In: MORENO, G.; HIGA, C.S. (Orgs.). Geografia de Mato Grosso. Cuiabá: Entrelinhas, 2005. p.102-122.

A política estadual e federal de colonização em Mato Grosso - 1900/1990. In: MORENO, G.; HIGA, C. S. (Orgs.). Geografia de Mato Grosso. Cuiabá: Entrelinhas, 2005. p.52-71.

MOREnO, G.; HIGA, C. S. (Orgs.). Geografia de Mato Grosso. Cuiabá: Entrelinhas, 2005.

NETO, C. S. V. Dinâmica urbana regional. In: MORENO, G.; HIGA, C. S. (orgs.). Geografia de Mato Grosso. Cuiabá: Entrelinhas, 2005. p. 156-170.

OLIVEIRA, V.C. da S. et al. Combinação de esforços públicos e privados em âmbito municipal: análise interpretativa de uma experiência contemporânea. In: CADERNOS EBAPE. BR. v. 7, $\mathrm{n}^{\mathrm{o}}$ 1, artigo 8, Rio de Janeiro: FGV, mar. 2009, p.114.134.

PEREIRA, Potyara A. P. Sobre a Política de Assistência Social no Brasil. In: BRAVO, Maria Inês S. e PEREIRA, Potyara A. P.(Orgs.). Política Social e Democracia. 2 ed. São Paulo: Cortez; Rio de Janeiro: UERJ, 2002.

PEREIRA, B. D. Mato Grosso: principais eixos viários e a modernização da agricultura. Cuiabá-MT: EdUFMT, 2007.

PREFEITURA MUNICIPAL DE JURUENA. Dados econômicos. Disponível em: $<$ http://www.pmjuruena.com. br/novo site/index.php? exibir $=$ secoes $\& I D=49>$. Acesso em: 14 nov. 2011.

SANDRONI, P. Novíssimo dicionário de economia. São Paulo: Ed. Best Seller, 1999.

SANTOS, M. A urbanização brasileira. 5. ed. São Paulo: Editora da Universidade de São Paulo, 2009.

SECRETARIA DE PLANEJAMENTO DO ESTADO DE MATO GROSSO (SEPLAN-MT). Anuário 2007. Disponível em: <http://www.zsee.seplan.mt.gov.br/anuario2007/index. html>. Acesso em: 14 ago. 2011.

. Anuário 2009. Disponível em: <http://www.zsee. seplan.mt.gov.br/anuario2009/index.html $>$. Acesso em: 14 ago. 2011 .

SIQUEIRA, E. M. O processo histórico de Mato Grosso. 2. ed. Cuiabá: UFMT, 1990.

SOUZA, E. A. Sinop: história, imagens e relatos: um estudo sobre sua colonização. Cuiabá-MT: Editora UFMT, 2004.

SECRETARIA ESTADUAL DE SAÚdE (SUS). Mato Grosso. Disponível em: <http://tabnet.datasus.gov.br/cgi/ tabcgi.exe?ibge/cnv/sanmt.def $>$. Acesso em: 09 jan. 2012.

TEIXEIRA, L. A colonização no Norte de Mato Grosso: o exemplo da Gleba Celeste. Dissertação (Dissertação em Geografia). 2006. Presidente Prudente: UNESP, 2006.
VILLAR, P. M. Del et al. Impacto do projeto de asfaltamento da BR-163: perspectivas da sociedade e do setor produtivo agrícola ao longo do eixo da Cuiabá Santarém. Brasília: s.n., 2005.

Recebido em: 16 de julho de 2012 Aceito em: 5 de outubro de 2012 